\title{
Formalização e precarização do trabalho canavieiro em tempos de reestruturação produtiva ${ }^{1}$
}

Allan Souza Queiroz ${ }^{2}$

Resumo: O objetivo desse artigo é analisar a formalização do trabalho rural na agroindústria canavieira de Alagoas. Durante os anos de 1990, a agroindústria introduziu medidas de reestruturação produtiva com o interesse de se modernizar e de se tornar competitiva. A aplicação de tais medidas engendrou a racionalização do processo de trabalho na agricultura. Dessa maneira, algumas mudanças ocorreram em relação ao em prego e ao processo de trabalho: a diminuição do trabalho vivo na agricultura; a institucionalização dos contratos de trabalho legais, dessa vez formais e flexíveis; e a intensificação do processo de trabalho manual, isto é, o aumento na carga de trabalho da atividade dos canavieiros. Baseado em um estudo teórico-bibliográfico sobre o processo de reestruturação produtiva, elabora-se uma análise sobre os vetores que impulsionaram a formalização de trabalho canavieiro.

Palavras-chave: Trabalhador canavieiro; relação salarial formal; precarização do trabalho; Alagoas (Brasil).

Abstract: The objective of this article is to analyze the formalization of rural work in the sugarcane industry of Alagoas. During the nineties, this industry introduced some principles of the productive reorganization in order to become modern and competitive. The application of such principles engendered the rationalization of work process in agriculture. Thus, some changes took place in relation to the employment and labour relations: the decrease of living labour in agriculture; the

\footnotetext{
1 Este artigo encerra estratos não publicados do nosso trabalho de conclusão de curso, intitulado Modernização, Reestruturação produtiva e Precarização do Trabalho nos Canaviais Alagoanos, apresentado no curso de Ciências Sociais/UFAL, no ano de 2011, sob orientação da professora Dra. Alice Anabuki Plancherel, a quem registro meus agradecimentos às inestimáveis contribuições ao meu desenvolvimento intelectual; estendo-os da mesma maneira à minha atual orientadora de mestrado em Sociologia da Universidade Federal do Rio Grande do Sul, professora Dra. Cinara Lerrer Rosenfield, de quem recebi também importantes contribuições.

2 Bacharel em Ciências Sociais pela UFAL, mestrando do Programa de Pós-Graduação em Sociologia da UFRGS e membro do Grupo de Pesquisa/CNPq Trabalho e Capitalismo Contemporâneo. E-mail: allan.queiroz@ufrgs.br.
}

Latitude, vol. 5, no 1 , pp. 55-83, 2011

DOI: https://doi.org/10.28998/2179-5428.20110103 


\section{Formalização e precarização do trabalho canavieiro em tempos de reestruturação produtiva.}

institutionalization of work contracts under the law, this time formal and flexible; and the intensification of manual work process, that is the increase of workload in the activity of sugar cane workers. Based on a theoretic-bibliographic study about the process of productive restructuration, elaborates on an analysis about the vectors that generated the formalization of sugarcane work.

Keyword: Sugarcane labourer; formal salaried relation, precarization of work, Alagoas (Brazil).

\section{Introdução}

O objetivo deste artigo é discutir a relação da institucionalização do assalariamento formal com a precarização do trabalho canavieiro na agroindústria canavieira do estado de Alagoas, desde a retomada da modernização do setor sucroalcooleiro em tempos de reestruturação produtiva.

No curso da década de 1990, as mudanças econômicas no setor sucroalcooleiro encerram efeitos no universo do trabalho canavieiro atingindo praticamente todo o conjunto dos trabalhadores rurais, naquela atividade, em Alagoas. Tais efeitos se estabeleceram seja em uma dimensão formal, via institucionalização de contratos diretos entre capital e trabalho, seja em uma dimensão concreta, pela intensificação do trabalho manual dos cortadores de cana, indicando mudanças no emprego e no trabalho, na parte agrícola da agroindústria açucareira. Levanta-se a hipótese de que tais elementos redimensionaram a histórica e estrutural precariedade do trabalho nos canaviais, ao produzir consequências sociais de degradação do trabalho e da saúde dos canavieiros.

A discussão que se propõe resgata, no plano teórico-conceitual, os aspectos gerais da reestruturação produtiva, para em seguida, compreender os aspectos específicos do fenômeno no setor sucroalcooleiro alagoano. A articulação do processo no âmbito macro-estrutural, com sua especificidade local, dar-se-á na mediação entre mudanças organizacionais e o processo de precarização nas condições laborais e de existência dos seus sujeitos. Por conseguinte, avança-se numa análise sobre os vetores que impulsionam a formalização do trabalho canavieiro na contemporaneidade, indicando seus efeitos sociais sob renovadas formas de legitimação da tensão entre capital agroindustrial e trabalho assalariado.

\section{As características da reestruturação produtiva}

O que se convencionou chamar de reestruturação produtiva diz respeito às mudanças e inovações organizativas das indústrias capitalistas, a partir de meados da década de 1970. No cerne da produção capitalista baseada em modelos 
taylorista e fordista de produção, notadamente disseminados no período anterior, surgem novos modelos. À esfera produtiva é imposto um rearranjo flexível, em um cenário de mundialização do capital, dos mercados e da concorrência entre empresas. Com a reorganização da produção, seguem-se mudanças na utilização do trabalho, por meio de estratégias empresariais de flexibilidade e a intervenção dos Estados Nacionais através da flexibilização do mercado de trabalho, causando impactos profundos na classe trabalhadora.

Dentre os principais modelos propostos como saída ao taylorismo/fordismo está o modelo japonês, concebido nas fábricas da Toyota. Segundo Alves (2000), esse modelo surgido no capitalismo japonês nos anos de 1950, mais conhecido como toyotismo, seria o momento ápice desse "complexo de reestruturação produtiva" a partir dos anos de 1980.

O que denominamos "complexo de reestruturação produtiva" envolve um sistema de inovações tecnológico-organizacionais no campo da produção social capitalista - por exemplo, a robótica e a automação microeletrônica aplicada à produção; as novas modalidades de gestão da produção, tais como os CQQ's e Programas de Qualidade Total; a série de racionalizações da produção, tais como os "downsizing" e a reengenharia (muitas das racionalizações produtivas decorreram de novos patamares de centralização e concentração do capital, por meio de fusões, aquisições e diversificações corporativas, que implicaram - e ainda implicam - demissões em massa). Além disso, é um importante componente do complexo de reestruturação produtiva, dos vários tipos de descentralização produtiva, tais como a terceirização ou as relocalizações industriais, que implicam o fechamento de fábricas num local e abertura em outro, ou ainda a instauração de novas legislações trabalhistas de cariz flexível, que criam nova regulação institucional do trabalho assalariado, adaptando-o às necessidades imperiosas do capital em processo (ALVES, 2000, p. 11).

A universalização dessas inovações tecnológico-organizacionais a partir da década de 1980, ressalta Alves (2000), deu-se em virtude da adequação do toyotismo à crise de superprodução do capitalismo. Décadas anteriores, ainda em 1950, a experiência japonesa em resposta a "o que fazer para elevar a produtividade quando as quantidades não aumentam?" (CORIAT, 1994 apud 


\section{Formalização e precarização do trabalho canavieiro em tempos de reestruturação produtiva.}

ALVES, 2000, p. 37) - isto é, a criação de uma alternativa ao modelo da produção em massa, com estoque e padronizada, difundido desde as fábricas Ford - tivera êxito sob a vigência do toyotismo. Décadas mais tarde, sua capacidade de sua inovação à crise da economia mundializada possibilitou a universalização do modelo japonês.

Para Harvey (2009), esse momento expressa a transição do fordismo a uma produção flexível, caracterizada pela mudança no "regime de acumulação"3 e no "modo de regulamentação social e política e ele associado". Fazendo uso do instrumental analítico da escola da regulação francesa, o autor vai definir esse momento, no qual localizamos a reestruturação produtiva, como o do estabelecimento do regime de acumulação flexível. Nas palavras do mesmo (2009, p. 141):

A acumulação flexível [...] é marcada por um confronto direto com a rigidez do fordismo. Ela se apoia na flexibilidade dos processos de trabalho, dos mercados de trabalho, dos produtos e padrões de consumo. Caracteriza-se pelo surgimento de setores de produção inteiramente novos, novas maneiras de fornecimento de serviços financeiros, novos mercados e, sobretudo, taxas altamente intensificadas de inovação comercial, tecnológica e organizacional. A acumulação flexível envolve rápidas mudanças dos padrões do desenvolvimento desigual, tanto entre setores como entre regiões geográficas, criando, por exemplo, um vasto movimento no emprego no chamado "setor de serviços" [...] Esses poderes aumentados de flexibilidade e mobilidade permitem que os empregadores exerçam pressões mais fortes de controle do trabalho sobre uma força de trabalho [...] A acumulação flexível parece implicar níveis relativamente altos de desemprego "estrutural" [...] ganhos modestos (quando há) de salários reais [...] e o retrocesso do poder sindical - uma das colunas políticas do regime fordista.

\footnotetext{
${ }^{3}$ Cf. Harvey (2009, p. 117): “Um regime de acumulação 'descreve a estabilização, por um longo período, da alocação do produto líquido entre consumo e acumulação; ele implica alguma correspondência entre a transformação tanto das condições de produção como das condições de reprodução de assalariados'”.
} 
O estabelecimento da acumulação flexível vai ao encontro, portanto, da flexibilidade dos processos produtivos ${ }^{4}$, consistindo não somente no desenvolvimento de novos limites de usufruto do trabalho, mas também na introdução de novas formas de emprego e novas regras sociais e culturais a serem compartilhadas. Resgatando um esquema ${ }^{5}$ trazido por Swyngedouw (1986 apud HARVEY, 2009, p. 169), apresentamos um resumo das principais tendências da acumulação flexível, nas mais diversas dimensões:

i) O processo de produção: em pequenos lotes, flexível e variada; sem estoques; controle da qualidade pela detecção imediata de erros; redução da porosidade do trabalho; voltada para a demanda;

ii) $O$ trabalho: múltiplas tarefas; pagamento pessoal via sistema detalhado de bonificações; desespecialização; treinamento no trabalho; organização do trabalho mais horizontal; ênfase na corresponsabilidade do trabalhador; elevada segurança no emprego para o núcleo qualificado e, nenhuma segurança no emprego e má qualidade das condições de trabalho para os trabalhadores temporários;

iii) O espaço: agrupamentos e conglomerados espaciais; integração espacial; diversificação do mercado de trabalho (segmentação interna); proximidade espacial de firmas verticalmente quase integradas;

iv) $O$ Estado: desregulação/re-regulamentação; flexibilidade; divisão/ individualização e negociações locais ou por empresa; privatização das necessidades coletivas e da seguridade social; desestabilização internacional; descentralização e agudização da competição inter-regional/interurbana; pesquisa e desenvolvimento financiados pelo Estado; inovação liderada pelo Estado;

v) A ideologia: consumo individualizado; pósmodernismo; $\quad$ especificidade/ adaptação; individualização/a sociedade do espetáculo.

\footnotetext{
${ }^{4}$ Por flexibilidade dos processos produtivos, entendemos “a flexibilização das estruturas produtivas e das formas de organização do trabalho intra e interempresas, bem como os processos de flexibilização da força de trabalho através do emprego e do não-emprego" (APPAY, 1997, p. 511).

${ }_{5}$ Originalmente o esquema compreende o contraste entre o fordismo e a acumulação flexível. Cf. Harvey (2009, p. 167).
} 


\section{Formalização e precarização do trabalho canavieiro em tempos de reestruturação produtiva.}

As tendências acima descritas expressariam diferenças em relação ao regime fordista mais vigente em um período anterior. Contudo, Harvey não elimina um dado grau de continuidade na transição do fordismo para a acumulação flexível.

A esse respeito, Alves (2000) comenta que o toyotismo "conseguiu 'superar', no sentido dialético (superar conservando), alguns aspectos predominantes da gestão da produção capitalista sob a grande indústria do século XX" (ALVES, 2000, p. 35). Se no modelo japonês, amplamente difundido na década de 1980, a racionalização do trabalho constitui um dos pilares para a obtenção da produtividade do trabalho, no fordismo/taylorismo isso não era diferente. A maneira de incrementar a acumulação capitalista continuou, portanto, sob a mesma "lógica produtivista" da grande indústria. Entretanto, sob bases subjetivas diversas daquelas no período anterior de produção fordista/taylorista, localização da ruptura entre os modelos.

O incremento nos lucros capitalistas constitui-se naquilo que Harvey (2009) julga mais importante para o momento de acumulação flexível, referente à constituição de um quadro de estratégias capitalistas já definidas por Marx, e que se mantém atual na contemporaneidade, no qual aparecem as formas absoluta e relativa de exploração do trabalho, que se combinam e se alimentam mutuamente.

A primeira, chamada de mais-valia absoluta, apoia-se na extensão da jornada de trabalho com relação ao salário necessário para garantir a reprodução da classe trabalhadora num dado padrão de vida. A passagem para o prolongamento das horas de trabalho, associadas com uma redução geral do padrão de vida através da erosão do salário real ou da transferência do capital corporativo de regiões de altos salários a regiões de baixos salários representa uma da faceta da acumulação flexível de capital [...] Nos termos da segunda estratégia, denominada mais-valia relativa, a mudança organizacional e tecnológica é posta em ação para gerar lucros temporários para firmas inovadoras e lucros mais generalizados com a redução dos custos dos bens que definem o padrão de vida do trabalho (HARVEY, 2009, p. 174).

Essas duas formas de extração de mais-valia garantem o lucro capitalista, pois é a parte do trabalho não pago ao trabalhador, é o epicentro da exploração do trabalho no modo de produção capitalista. No âmbito da acumulação flexível, segue um processo de segmentação do mercado de trabalho, no qual se 
reproduzem formas igualmente combinadas de força de trabalho altamente qualificada e desqualificada, em relação àquelas duas formas de mais-valia. Uma divisão do trabalho no qual o trabalho intelectual, mais especializado, torna-se "um estrato altamente privilegiado e até certo ponto poderoso da força de trabalho, à medida que o capitalismo depende cada vez mais da mobilização de forças de trabalho intelectual como veículo para mais acumulação";e o trabalho manual, desqualificado que ressurge em "sistemas de trabalho doméstico, familiar e paternalista" (HARVEY, 1998, p. 2011). É nesse sentido que a acumulação flexível articula ao cenário produtivo uma nova via de subordinação do trabalho ao capital, seja recriando antigas formas de trabalho, e novas formas de trabalho, resultado das novas tecnologias organizacionais da produção.

Atributos como a polivalência operária são aprofundadas nesse cenário, caráter interpretado enquanto uma desespecialização (ANTUNES, 1998; ALVES, 2000). A desespecialização se concretiza onde se requerem assalariados desempenhando diversas atividades, principalmente no trabalho industrial, cujas atividades passam a se situar no âmbito da supervisão e não necessitam de um conhecimento notadamente especializado.

Antunes (1998, p. 47) ressalta: "[...] paralelamente à redução quantitativa do operariado industrial tradicional dá-se uma alteração qualitativa na forma de ser do trabalho, que de um lado impulsiona para uma maior qualificação do trabalho e, de outro, para uma maior desqualificação" ${ }^{6}$. Assim, a desespecialização de certos grupos atua coordenada com a elevada especialização de outros; um processo contraditório no qual ora se requer um trabalhador polivalente, desqualificado, ora se exigem trabalhadores com conhecimentos específicos, altamente especializados e qualificados, necessários para operar maquinários e funções em diversos setores mais diferenciados entre si.

$\mathrm{O}$ ato de trabalho, sob esse novo regime de acumulação, acontece em equipe e faz parecer aos trabalhadores que eles são protagonistas na decisão dos rumos da empresa, cabendo-lhes certa responsabilidade para a manutenção dos postos de trabalho e efetivação dos lucros, mas não para a partilha destes; nada mais

${ }^{6}$ Cf. Sobre a tendência à desqualificação dos trabalhadores, comenta Antunes (1998, p. 52 grifos do autor): "Paralelamente a esta tendência se acrescenta outra, dada pela desqualificação de inúmeros setores operários, atingidos por uma gama diversa de transformações que levaram, de um lado, à desespecialização do operário industrial oriundo do fordismo e, por outro, à massa de trabalhadores que oscila entre os temporários (que não tem nenhuma garantia no emprego), aos parciais (integrados precariamente às empresas), aos subcontratados, terceirizados (embora se saiba que há, também, terceirização em segmentos ultraqualificados), aos trabalhadores da 'economia informal', enfim, a este enorme contingente que chega até a faixa de $50 \%$ da população trabalhadora dos países avançados, quando nele se incluem também os desempregados, que alguns chamam de proletariado pós-industrial e que preferimos denominar de subproletariado moderno". 


\section{Formalização e precarização do trabalho canavieiro em tempos de reestruturação produtiva.}

acontece do que a conquista ideológica dos trabalhadores que passam a efetuar o controle mútuo entre si, contribuindo para a fragmentação da classe trabalhadora, uma vez que não se está lutando pelo controle social da produção e sim "jogando" conforme as regras do empregador. É nesse momento que a identidade operária é ressignificada, surgindo novas categorias, como aquelas dos colaboradores.

Opera-se uma nova forma de gerenciamento da força de trabalho que busca, no estabelecimento de compromissos, pelo viés participativo, a manipulação da subjetividade operária. Sorrateiramente, uma nova cultura organizativa da participação encerra a intensificação do processo de trabalho, baseada no comprometimento com a qualidade total, nos produtos e serviços realizados pelos trabalhadores, consistindo num efetivo dispositivo disciplinário. ${ }^{7}$

Ao mesmo tempo, diminui-se o contingente de trabalho vivo empregado, seja pela incorporação de tecnologias ou de novos métodos de gestão que aumentam a produtividade, enxugando o efetivo real de trabalhadores. Nesse sentido, os mecanismos da reestruturação produtiva têm em vista potencializar o ganho em produtividade proporcionada pela extração da mais valia relativa. Ao mesmo tempo, são recriadas formas de trabalho que garantem a extração da mais valia absoluta do trabalho vivo.

Nesses segmentos da classe trabalhadora que ocupam as atividades menos qualificadas, seu recrutamento flexível e barateado recobre aquelas atividades laborais que conheceram uma intensificação em seu ritmo e cadência. Para o trabalhador, a intensificação do processo de trabalho manual trouxe consequências que extrapolaram o momento do trabalho em si, para outras esferas da vida social.

Não por acaso demissões em massa acontecem, sobretudo a partir da década de 70, motivadas pelas novas tecnologias da produção que possibilitam a diminuição considerável do trabalho, não somente nos chãos de fábrica, mas também em outros setores nos quais aquelas estratégias foram implementadas.

Ao mesmo tempo, os níveis de sindicalização deprimem no mundo inteiro, tendência corroborada pelas estratégias de cooptação dos sindicatos, previstas e implementadas pelo ideário toyotista, pela criação dos sindicatos-empresa que deixam de lutar pelo controle da produção por parte dos trabalhadores, auxiliando no êxito político do capital sobre o trabalho e retrocedendo no que tange aos processos de individualização e fragmentação da classe trabalhadora.

O Estado atuou decisivamente nesse processo, coordenando boas partes dessas mudanças no âmbito jurídico-legal. Seu papel de (re)mediador das tensões entre capital e trabalho passa a ser orientado pela agenda neoliberal, engendrando novas institucionalidades que abarcam os sistemas de emprego e os mercados de trabalho. Esse movimento consistiu numa reestruturação pela flexibilidade,

${ }^{7}$ Cf. Sanchez (2005), sobre a produção da disciplina entre os trabalhadores nas fábricas espanholas de máquinas-ferramentas. 
permitindo os ajustes e controle mais dinâmico da força de trabalho pelo capital, na medida das flutuações econômicas.

A categoria da flexibilidade, apanágio da produção capitalista desde seus primórdios, permanece estratégica para a acumulação do capital, conforme sustenta Alves (2000, p. 24), nos termos da:

[...] flexibilidade relativa à legislação e regulamentação social e sindical, na qual um aspecto muito discutido é o que diz respeito à flexibilidade nos contratos de trabalho: a possibilidade de variar o emprego (volume), os salários, horários e o local de realização do trabalho dentro e fora da empresa [...] (2000, p. 24).

Vasapollo (2005, p. 25) salienta que todo esse processo de mudança nas dinâmicas de acumulação do capitalismo provocou a "redefinição do papel do Estado e de sua relação com o mercado" quando da passagem do Estado de bemestar social para o Estado neoliberal ${ }^{8}$ - antes, o antigo Estado providência, que garantia os direitos dos trabalhadores foi um obstáculo a ser eliminado (VASAPOLLO, 2005). No caso brasileiro, esse processo de diminuição do controle do Estado no mercado de trabalho está em curso desde meados dos anos de 1980 e aprofunda-se nos anos 90 (CARDOSO JR., 2001).

É nesse sentido que essas mudanças no mercado de trabalho podem ser lidas como uma desregulamentação do trabalho que vai de encontro aos interesses da classe trabalhadora, posto que agora é obrigado a vender sua força de trabalho em condições muito menos vantajosas do que num período anterior, isto é, de maneira muito mais lábil, temporária, barateada e desprotegida socialmente. Esse processo que atinge diferentes segmentos da classe trabalhadora, segundo Antunes (1998, p. 44) baseado em Bihr (1991),

[...] têm em comum a precariedade do emprego e da remuneração; a desregulamentação das condições de trabalho em relação às normas legais vigentes ou acordadas e a consequente regressão dos direitos sociais, bem como a ausência de proteção e expressão sindicais, configurando uma tendência à individualização extrema da relação salarial.

${ }^{8}$ Estado social e Estado pós-fordista, conforme os termos de Vasapollo (2005). 


\section{Formalização e precarização do trabalho canavieiro em tempos de reestruturação produtiva.}

Os efeitos do enfraquecimento dos coletivos de trabalho renderam saldos positivos ao capital, que contou com a regulamentação a seu favor. A flexibilidade seria também essa maneira elástica de contratação da força de trabalho, de acordo com a demanda dos mercados. Essas mudanças são preocupantes, pois se institucionalizam dando um caráter de legitimidade à exploração do trabalho nas mais variadas situações de intermitência, presença, intensidade e preço a ser pago. Assim, segundo Vasapollo (2005, p. 28): “a flexibilização [...] é uma imposição à força de trabalho para que sejam aceitos salários reais mais baixos e em piores condições".

A desregulamentação do mercado do trabalho, segundo Cardoso Jr. (2001), é só uma das pontas de um processo mais amplo de desregulação do mundo do trabalho. Segundo esse autor, a desregulação do trabalho implica tanto a desestruturação quanto a desregulamentação. A desestruturação caracteriza-se, entre outros elementos, pelo aumento vertiginoso do setor de serviços, um aumento "não desprezível" dos níveis de desemprego (e desocupação) e pela precarização dos postos de trabalho, agora informais, temporários, flexibilizados. Já a desregulamentação do mercado de trabalho expressa-se pela pulverização de antigas seguranças sociais inscritas na legislação trabalhista, por meio da flexibilização das leis na condição de uso da força de trabalho, como a possibilidade da contratação de trabalhadores por tempo determinado e a criação do banco de horas (CARDOSO JR., 2001).

Em suma, essas medidas visam recrudescer o barateamento do uso da força de trabalho, flexibilizando a contratação e demissão dos trabalhadores, diminuindo e/ou subtraindo os encargos trabalhistas nas contas dos empregadores. No Brasil, por exemplo, a disseminação de contratos por tempo determinado representou uma diminuição nos custos dos empregadores que incidem diretamente nas garantias sociais dos trabalhadores. Posto que nesse contrato, diminui-se

de $8 \%$ para $2 \%$ a contribuição patronal ao FGTS, além do não pagamento, pelo empregador, da multa de $40 \%$ sobre o saldo do FGTS do trabalhador no momento da rescisão do contrato de trabalho. Por fim, haveria uma redução no preço das horas extraordinárias realizadas sob a vigência de contratos de trabalho por tempo determinado (CARDOSO JR., 2001, p. 50).

Na contemporaneidade, o que antes era tangencial ao mercado formal de trabalho no capitalismo, como o trabalho informal, precário, parcial, temporário, terceirizado, "passa a ter um lugar estratégico e central na lógica da dominação capitalista, deixando de ser algo residual ou periférico, para ir se institucionalizando em todo lugar e em todas as regiões do mundo, tanto nos 
Allan Souza Queiroz

países desenvolvidos e centrais, como em países como o Brasil" (DRUCK e FRANCO, 2009, p. 227).

Para Vasapollo (2005), há um aumento considerável na oferta de trabalho "atípico": isto é, aquele trabalho que diverge de um padrão estabelecido nos anos dourados do fordismo. A atipicidade repousa sobre as novas condições impostas aos trabalhadores: um trabalho temporário ou parcial, onde não existe tempo integral de horas de trabalho, no qual há omissão de normas que definam quem é o assalariado e ausência de "tutela formativa ou contratual" que assegure garantias mínimas à vida de quem trabalha.

Decerto, é a partir do processo de reestruturação produtiva mundialmente em curso nos anos 90, que os trabalhadores passam a vivenciar novas formas de precarização em suas condições de trabalho. O cerne principal dessas mudanças consiste na disseminação de novas formas de usufruto do trabalho e no aumento do desemprego, surgindo categorias como os demandantes de emprego, ou mesmo, os não empregáveis, que estariam à margem do mercado de trabalho.

\section{As mudanças no mundo do trabalho}

Diante das mudanças vigentes no capitalismo a partir de meados da década de 1970, como também da crise no sindicalismo, do desemprego estrutural e da emergência de novas e antigas formas de trabalho, análises sociológicas promoveram o adeus à classe trabalhadora, e consequentemente, à centralidade do trabalho, cuja tese mais famosa foi elaborada por Gorz (1987).

Para o autor francês, um dualismo societal estabelecera-se desde as mudanças no capitalismo daquele período, entre esferas de autonomia e heteronomia. Esta última esfera, baseada no trabalho social tipicamente capitalista, representada pela "classe operária tradicional [que] não passa de uma minoria privilegiada" estaria perdendo sua centralidade, face à ampliação daquela primeira esfera, baseada no tempo livre - o reino das atividades autônomas -, e por sua vez, representada pelo "neoproletariado pós-industrial dos sem-estatuto e dos semclasse que ocupam os empregos precários de ajudantes, de tarefeiros, de operários de ocasião, de substitutos, de empregados em meio expediente" (GORZ, 1987, p. 89).

No alargamento da esfera da autonomia, cuja centralidade não estaria mais no trabalho", prefiguraria "a dissolução de todas as classes, aí incluída a classe

${ }^{9}$ Cf. Gorz (1987, p. 89): “O neoproletário geralmente é superqualificado com relação ao emprego que encontra. Está condenado ao desemprego de suas capacidades enquanto espera pelo desemprego puro e simples. Todo emprego, para ele, tem um caráter acidental e provisório, e todo trabalho uma forma contagiante. Para ele é impossível investir-se em 'seu'trabalho, identificar-se com 'seu'emprego. O trabalho deixa de ser, para ele, uma 


\section{Formalização e precarização do trabalho canavieiro em tempos de reestruturação produtiva.}

trabalhadora", isto é, desenhar-se-ia a própria ultrapassagem do capitalismo. Gorz parece fazer eco a uma visão mais imediatista que confunde as transformações na classe trabalhadora contemporânea, em tempos de reestruturações econômicas, com um novo patamar societário a se delinear. Confunde também a categoria trabalho em geral - aquela definida por Marx como condição da existência humana - com todos os empregos assalariados no capitalismo de seu tempo. Três décadas após a publicação de sua obra, a sociologia do trabalho vem rediscutindo a esfera da autonomia. Nesta, novas formas de vínculo entre capital e trabalho, baseiam-se igualmente, mutatis mutandis, na instrumentalização do tempo e da força de trabalho, promovendo novas tensões entre capital e trabalho.

$\mathrm{Na}$ contramão daquela interdição da centralidade do trabalho, Antunes (1998) traz a noção de "classe-que-vive-do-trabalho" para designar as formas metamorfoseadas da classe trabalhadora. Noção elaborada em conformidade com o "processo de maior heterogeneização, fragmentação e complexificação da classe trabalhadora" (ANTUNES, 1998, p. 42), o autor promove uma ampliação da categoria sociológica e política da classe trabalhadora, que deveria abarcar, não somente aquelas categorias vinculadas ao trabalho formal ou típico, mas também todas as outras categorias que emergem - sejam antigas, sejam novas - com as mudanças trazidas pela acumulação flexível.

O que as unem nesse momento? A reprodução de si pela venda de sua força de trabalho, podendo ou não estar diretamente vinculadas a uma organização do tempo socialmente necessário, mas que concretamente vendem sua capacidade de trabalho a outrem. Sobre a ampliação da categoria, comenta Antunes (2002 apud ORGANISTA, 2006, P. 38):

[...] a classe-que-vive-do-trabalho deve incorporar também aqueles e aquelas que vendem sua força de trabalho em troca de salário, como o enorme leque de trabalhadores precarizados, terceirizados, fabril e de serviços, part time, que se caracteriza pelo vínculo de trabalho temporário, pelo trabalho precarizado, em expansão na totalidade do mundo produtivo. Deve incluir também o proletariado rural, os chamados boiasfrias das regiões agroindustriais, além, naturalmente, da totalidade dos trabalhadores desempregados, que se

atividade ou mesmo uma ocupação principal para se tornar um tempo morto à margem da vida, onde se está 'ocupado' em ganhar algum dinheiro. Diferentemente do proletário de Marx, o neoproletário não se define mais por 'seu' trabalho e não pode ser definido por sua posição no interior do processo social de produção". 
constituem nesse monumental exército industrial de reserva.

Com essa noção, o referido autor procura reiterar a centralidade do trabalho, por ser esta atividade a força motriz da sociabilidade capitalista contemporânea. Independente da forma concreta sob a qual apareça, é a atividade de trabalho nos diversos setores que produz a riqueza material necessária à vida social, que na contemporaneidade assume a forma de trabalho abstrato. Mas, não somente isso, nesse momento: os produtores de toda a riqueza material vivenciam um processo cada vez mais intenso de precarização social, e esse contingente torna-se central no mundo do trabalho contemporâneo. Parte desse processo de precarização social pode ser explicado nas relações de trabalho, que são diversificadas em suas formas concretas. Nas palavras de Antunes (1998, p. 46 - grifos do autor), essa diversificação se traduz pela:

[...] nítida redução do proletariado fabril, industrial, manual, especialmente nos países de capitalismo avançado, quer em decorrência do quadro recessivo, quer em função da automação, da robótica e da microeletrônica, gerando uma monumental taxa de desemprego estrutural. Paralelamente a essa tendência, há outra também extremamente significativa, dada pela subproletarizaçao do trabalho, presente nas formas de trabalho precário, parcial, temporário, subcontratado, 'terceirizado', vinculadas à economia 'informal', entre tantas modalidades existentes.[...] Além da desproletarizaçao relativa do trabalho industrial, da incorporação do trabalho feminino, da subproletarizacao do trabalho, através do trabalho parcial, temporário, temse, como outra variante deste múltiplo quadro, um intenso processo de assalariamento dos setores médios, decorrentes da expansão do setor de serviços.

Entra em vigor uma "processualidade contraditória" (ANTUNES, 1998, p. 42 - grifo do autor) em que "de um lado, reduz o operariado industrial e fabril; de outro, aumenta o subproletariado, o trabalho precário e o assalariamento no setor de serviços. Incorpora o trabalho feminino e exclui os mais jovens e os mais velhos".

Destarte, em tempos de reestruturação produtiva, está em jogo uma reconfiguração na relação entre capital e trabalho caracterizada cada vez mais "pela precariedade, pela flexibilização e desregulamentação, de maneira sem 


\section{Formalização e precarização do trabalho canavieiro em tempos de reestruturação produtiva.}

precedentes para os assalariados [...] É o processo que precariza a totalidade do viver social" (VASAPOLLO, 2005, p.27).

Essa precarização social representou consequências sociais e políticas nunca antes vistas no mundo do trabalho, entendidas como uma intensa fragmentação e segmentação no seio da classe trabalhadora, cujos diversificados segmentos vivenciam diferentemente os efeitos sociais das mudanças econômicas.

De tudo que foi dito, busca-se ressaltar que esse momento de reestruturação produtiva, que encerra a flexibilidade e a externalização da força de trabalho, tem como resultado, o processo de precarização social. O trabalho precário consiste na base social sob a qual certos ramos de empresas que efetivaram reestruturações na organização da produção, vão desenvolver suas performances econômicas.

\section{A precarização do trabalho}

Para Demazière (2006), a sociologia vem contribuindo mais para alargar e enriquecer a noção de precariedade do que para fornecer uma definição precisa da mesma. Esse alargamento operado pelos sociólogos em torno da questão da precariedade do emprego e do trabalho, e do processo de precarização, antes de solucionar peremptoriamente o debate, acabou por conceder novos contornos ao exame das transformações do mundo do trabalho, bem como alavancar os estudos para um patamar mais complexificado, que mobiliza métodos quantitativos e qualitativos de pesquisa, e o trânsito entre as escalas macro e microssocial na investigação dos fenômenos.

Conforme o supracitado autor, a precariedade consiste numa noção refratária à descrição controlada e à medição, entretanto, é necessário falar-se dela, devido ao cenário do mundo do trabalho no presente século. A existência de formas de emprego específicas ou particulares que diferem do referencial estabilizado até os anos de 1970, vem sendo imposta pelas estratégias dos empregadores de maneira unilateral que conformam o "estandarte ideológico" do novo espírito do capitalismo, o qual radicaliza a experiência da descontinuidade e da intermitência nas formas de inserção laboral contemporâneas, repercutindo em frágeis trajetórias laborais e incertezas quanto ao futuro profissional.

Assim, a experiência da precariedade deve ser trazida ao seio dos estudos de sociologia do trabalho, nesse momento em que as relações entre capital e trabalho redundam na permanência das relações de exploração-dominação do trabalho, sob novas formas e normas de assalariamento, em contextos específicos. Cabe somente acrescentar mais um colorido à temática do que operar uma definição conclusiva. Isso nos leva a buscar como as definições colocadas pela literatura podem auxiliar na apreensão do fenômeno da precarização do trabalho canavieiro em Alagoas e contribuir para novas leituras do mesmo. 
Indica-se ainda que uma breve revisita à literatura que se debruça sobre o mundo do trabalho, exprime uma polifonia e variação na utilização do termo. Assim, precariedade do trabalho, precariedade do emprego, precarização do trabalho, precarização do emprego, precarização social, precárias condições de trabalho, inserção precária no mercado do trabalho etc., fazem parte do elenco de termos que tentam explicar o fenômeno das transformações do mundo do trabalho, em diferentes realidades empíricas, no que diz respeito à ampliação de formas inseguras, instáveis, temporárias, barateadas e aviltantes de usufruto do trabalho vivo, que redundam não somente na degradação da vida de quem trabalha, mas também na dissolução dos laços sociais por novas lógicas de individualização da relação salarial. Para uma síntese introdutória do conjunto de fenômenos a que nos referimos quando circundamos a noção de emprego precário no capitalismo, recorremos a Humblet \& Dorssemont (2012, p. 245) que nos informam o seguinte:

Os empregos podem sempre ser considerados como precários se são empregos se caracterizando por uma estabilidade frágil ou nula, um salário baixo ou não garantido, um acesso nulo ou insuficiente à seguridade social (em matéria de pensão, de seguro doença, de seguro desemprego), nenhum controle sobre o processo de trabalho pela presença ou ausência de sindicatos, ligado ao controle das condições de trabalho, dos salários e das cadências de trabalho, nenhuma proteção contra as demissões, nenhum acesso à formação profissional, sem perspectivas de carreira, pouca ou nenhuma saúde e segurança no local de trabalho, nenhuma proteção jurídica ou contratual e nenhuma representação sindical. ${ }^{10}$

Atrela-se ao debate da precarização, ainda uma discussão sobre a novidade do fenômeno. Seria esse um componente distintivo das relações de trabalho atuais? ${ }^{11}$ Qual o papel da precarização no histórico do mercado de trabalho assalariado brasileiro? Essas perguntas nos remetem a uma interpretação de como se deu a regulamentação do mundo do trabalho brasileiro e sua relação com o processo em escala mais global, e auxilia na identificação do contorno do fenômeno no contexto da agroindústria canavieira.

Assim, de maneira geral, um contrato padrão de emprego (standard employment relationship) se estabilizou no período pós-guerras, com maior

${ }^{10}$ Texto original em francês. A citação foi traduzida pelo autor do presente texto.

${ }^{11}$ A esse respeito, cf. Cingolani (2007), bem como Bihr (2007). 


\section{Formalização e precarização do trabalho canavieiro em tempos de reestruturação produtiva.}

amplitude nos países centrais da economia capitalista, e consistiu na marca distintiva da produção fordista. Sobre o assunto, comenta Krein (2007, p. 107, citado por MARCELINO, 2011, p.60):

[...] as características principais das relações de trabalho predominantes no pós-guerra são: centralização das negociações; reconhecimento dos sindicatos; restrições à dispensa de pessoal, sub-contratação ou emprego de pessoal eventual; controle sindical sobre alocação das tarefas e procedimentos de promoção dos trabalhadores; formulação de políticas salariais de longo prazo com incorporação de parte dos ganhos de produtividade, jornada padrão de 8 horas; sistema de proteção em caso de doença, desemprego e velhice; e o desenvolvimento de políticas sociais que permitiam a elevação indireta dos salários.

Esse padrão tornou-se a forma típica de contrato, fruto da regulação social do mercado de trabalho que orientou a maneira de usufruto do trabalho nos diversos setores da economia até o início dos anos de 1970 (MARCELINO, 2011).

No caso brasileiro, o trabalho típico ficou mais conhecido como o "trabalho em tempo integral, com um único empregador, relativa estabilidade e remuneração fixa e mensal, tendo relação com o tempo de permanência no emprego e a formação profissional e dando uma perspectiva de carreira e de segurança" (KREIN, 2007, p. 112).

Adita-se a essas condições "indicadores de qualidade, tais como rendimento, benefícios não salariais, proteção social (pensões, saúde, proteção no desemprego), indenizações por acidentes e doenças ocupacionais e oportunidades de qualificação profissional, entre outros" (GALEAZZZI \& HOLZMANN, 2011, p. 260).

Vale salientar que o trabalho formal não se generalizou no Brasil, nem temporal nem geograficamente, porém constituiu a maneira pela qual o direito do trabalho cristalizou o uso da força de trabalho assalariada no país (MARCELINO, 2011) ${ }^{12}$, e a forma de regulamentação do trabalho que orienta a proteção social do Estado até os dias atuais (CARDOSO JR., 2009).

12 Cf. Marcelino (2011, p. 61): “[...] se a condição geral da maioria dos trabalhadores for pensada em termos numéricos, talvez não haja uma tipicidade (temporal e geográfica) do contrato com essas características nem no auge do período desenvolvimentista, e muito menos nesses tempos de reestruturação produtiva e neoliberalismo". 
Nesse sentido, pode-se dizer que, pelo menos até os anos de 1990, antes da flexibilização das leis trabalhistas no país, houve um padrão de empregos no Brasil, marcado pelo paradoxo de não ter-se abrangido, porém, ter-se constituído nos referenciais simbólico e objetivo de todo trabalhador, marcado pela posse da "carteira assinada", e pelo histórico das lutas, mormente levadas a cabo pelos sindicatos de trabalhadores no período anterior.

Isso é importante de ser trazido, pois um dos setores em que não ocorreu a consolidação de um padrão de trabalho típico no país foi o mundo do trabalho rural. Quando alguma formalização alcança o mundo rural e as atividades produtivas da agricultura, já estamos em uma fase de retração da formalização no país, e surgimento de outras formas de trabalho e emprego, marcadas pela flexibilização.

Destarte, é um processo multifacetado que exige esforço analítico para entender o surgimento do assalariamento formal na agricultura, num momento em que a informalidade crescia e se ampliava nas atividades urbano-industriais e no setor de serviços. Esse esforço expressa a própria dificuldade de empregar a noção de precarização, termo mais difundido em contextos urbanos. Sobre o termo precarização, comenta Marcelino (2011, p. 65):

A palavra precarização está associada às ideias de instabilidade, de provisório, de fragilidade, de incerteza; todas palavras que remontam ao padrão de exploração capitalista anterior ao pós-guerras e que ganham novos significados com as condições de trabalho que vêm sendo desenhadas desde o início da década de 1970.

Esse sentido mais atual de precarização ganha terreno quando aquelas condições típicas, acima destacadas, passam a dar lugar a outras formas de trabalho.

Thebaud-Mony (2011) fala nesse processo enquanto uma "desorganização" do trabalho, que traduziria criticamente a "modernização pela flexibilidade", produzindo uma relação contratual flexível, temporária e desprotegida legalmente. Indica então que flexibilidade e precariedade estariam indissoluvelmente ligadas.

Por sua vez, Druck (2011, p. 41) nos informa sobre um quadro mais amplo de precarização social do trabalho, na contemporaneidade, da seguinte forma: "[...] compreendida como um processo em que se instala - econômica, social e politicamente - uma institucionalização da flexibilidade e da precarização moderna do trabalho, que renova e reconfigura a precarização histórica e estrutural do trabalho no Brasil".

Apesar dos estudos das duas últimas autoras concentrarem-se mais no fenômeno da terceirização, que de mero apêndice do mundo do trabalho, tornou- 


\section{Formalização e precarização do trabalho canavieiro em tempos de reestruturação produtiva.}

se central nesse momento de reestruturações produtivas, a discussão em torno da precarização do trabalho parece abranger todo o coletivo dos trabalhadores.

\section{A agroindústria canavieira de Alagoas em tempos de reestruturação produtiva}

Registra-se na literatura sobre a história do açúcar em Alagoas, um primeiro processo de modernização a partir da década de 1950, no qual, por um lado, ocorreu a consolidação dos parques industriais usineiros, mais produtivos em relação aos tradicionais engenhos banguês e, por outro, houve a expansão dos canaviais sobre a região dos tabuleiros, na parte sul da Zona da Mata alagoana. Esse processo significou a redefinição espacial da própria agroindústria, que ocupava, principalmente, a parte central e norte da região canavieira. Essa ampliação da estrutura fundiária, que se ligava à agroindústria, vinculou à modernização do setor um caráter extensivo de produção - passou-se a produzir mais, em uma maior extensão de terra, sem incorporação da mecanização na colheita.

A partir da década de 1990, o setor sucroalcooleiro do estado de Alagoas é tomado pela desregulamentação com o fim do Instituto do Açúcar e do Álcool13, órgão estatal que interveio no setor em âmbito nacional desde a década de 1930. No plano econômico, explica Carvalho (2009, p. 48):

A desregulamentação do setor sucroalcooleiro, ainda que mantendo antigas práticas, como a fixação de cotas e o planejamento de safras, tornou livres os preços do açúcar cristal, do álcool e da cana; liberalizou o mercado nacional, eliminando a reserva de mercado para o açúcar no Nordeste, até então monopolizado pelos produtores regionais; e privatizou as exportações, que passaram a ser feitas diretamente pelas usinas ou por tradings, colocando os principais e assimétricos centro produtores de açúcar em igualdade formal na disputa pelos mercados nordestino e externo.

\footnotetext{
${ }^{13}$ O Instituto do Açúcar e do Álcool (IAA) foi criado em 1933. Esse órgão passou a subsidiar o capital agroindustrial e induziu processos de modernização por meio de leis, programas e políticas que financiaram a expansão do setor. Segundo Carvalho (2009, p. 22), baseado em Rezende (1993): “O Estado, por meio do IAA, exercia influência sobre o mercado interno, fixando preços e monopolizando as compras. Regulamentava, também, o transporte, o manuseio e a armazenagem de açúcar".
} 
A abertura do mercado com o fim da intervenção estatal, quando da extinção do IAA, equiparou formalmente as empresas em condições desiguais de competição comercial ${ }^{14}$ e desencadeou novos processos de modernização do setor em solução àquelas desvantagens.

Entretanto, a desregulamentação setorial não fora um processo cabal. Em meio ao ambiente econômico pós-desregulamentação e diante de novas dificuldades na concorrência entre mercados nacionais e internacionais, o Estado, por meio da Superintendência de Desenvolvimento do Nordeste (Sudene), elaborou novas políticas públicas que

[...] objetivam facultar ao setor sucroalcooleiro o tempo necessário para a racionalização da área plantada, o aumento do investimento em tecnologias, tanto fabris como agrícolas, a criação de aparato de pesquisa que se adeque à realidade sub-regional, revertendo as dificuldades da mecanização no corte da cana em razão da topografia, a baixa utilização de maquinaria e equipamentos, a baixa produtividade da mão-de-obra, a ausência de pesquisas de novas tecnologias da produção industrial e, principalmente, de cultivo que resultam em custos de produção mais elevados. Esse pacote, posto em prática, reverteria a baixa remuneração dos produtores, tanto rurais como industriais (SUDENE, 1997 apud CARVALHO, 2009, p. 70).

Assim, segundo comenta Carvalho (2009), na década de 1990, novos recursos são repassados ao setor, especialmente para os fornecedores de cana. Além disso, alternativas são criadas pelo novo ambiente institucional, que exige a busca de medidas em torno da competitividade nacional e internacional. Nesse cenário, o capital agroindustrial alagoano passa por um novo momento, responsável "pelo processo de reestruturação produtiva ocorrido no complexo sucroalcooleiro alagoano, com a desativação de algumas usinas e destilarias e a concentração da produção nas mãos de um grupo menor de unidades industriais" (CARVALHO, 2009, p. 50).

${ }^{14}$ Cf. Carvalho (2009, p. 69): “A produtividade média agrícola em Alagoas situa-se em torno de 50t/ha, enquanto que no Sudeste se atingem médias acima de $80 t / h a$. O rendimento industrial em Alagoas oscila em torno de $100 \mathrm{~kg}$ de açúcar por tonelada de cana esmagada, enquanto a média no Sudeste é de $110 \mathrm{~kg} / \mathrm{t}^{\prime \prime}$. 


\section{Formalização e precarização do trabalho canavieiro em tempos de reestruturação produtiva.}

Naquele período, as empresas buscaram estratégias de intensificação da produção, aumento da produtividade e redução dos custos (CARVALHO, 2009). Novas tecnologias são adotadas na parte industrial, os quadros da parte administrativa e comercial são qualificados, e na parte agrícola novos métodos de gestão do trabalho são adotados, objetivando o sucesso daquelas medidas.

Uma das modificações que a reestruturação produtiva traz para a agroindústria alagoana é a alternância para o modelo intensivo de produção, o qual diz respeito ao aumento da produtividade setorial, redução da área plantada e flexibilidade na produção, incidindo na transformação qualitativa de características à qual o processo de modernização da agricultura, iniciado nos anos de 1950 não deu solução, a exemplo da expansão horizontal da produção e do baixo rendimento industrial - elementos característicos de uma produção extensiva (CARVALHO, 2009).

Para se ter uma ideia da conversão a uma produção canavieira intensiva, dados informam que em aproximadamente 20 anos (1987-2007), o setor reduziu 1/3 da área plantada - de 687 mil hectare (ha) na safra de 1987, para 438,57 mil ha na safra 2010/2011 15 e aperfeiçoou sua produtividade industrial, igualando esta à de São Paulo. ${ }^{16}$

A diminuição em extensão dos canaviais alagoanos e o aumento da produtividade sinalizam uma expansão vertical na produção, apanágio da reestruturação produtiva, que engendra, setorialmente, "importantes transformações tecnológicas no processo de produção e na organização do trabalho" (PADRÃO, 1997, p. 133).

O aumento da produtividade agrícola é atingido, sobretudo, em decorrência de mudanças no trabalho manual realizado permanente e sazonalmente nos canaviais de Alagoas. Naquela época, a permanência do trabalho manual, deve-se, dentre outros motivos, aos limites socioeconômicos dos usineiros em desenvolver a mecanização da colheita, bem como aos limites naturais impostos à inserção tecnológica nos terrenos acidentados da Zona da Mata. A título de registro, salienta-se aqui que a reticente mecanização da colheita, presentemente em curso, estabelece-se, mormente na parte sul da Zona da Mata, onde se encontram os tabuleiros, terrenos mais planos e suscetíveis à mecanização. Na parte norte da Zona da Mata, sua topografia acidentada e aladeirada formada por encostas e serras conta quase que exclusivamente com o trabalho vivo para a realização da colheita. Deve-se lembrar, contudo, que a mecanização está presente em outras etapas do processo de produção da matéria prima agrícola que alimenta as usinas,

${ }^{15}$ Dados de Carvalho (2009) e CONAB (2011).

16 Informações retiradas de entrevista concedida pelo economista e especialista da reestruturação produtiva em Alagoas, Cícero Péricles de Carvalho, a membros do Grupo de Pesquisa/CNPq Trabalho e Capitalismo Contemporâneo em 08/04/2010. 
a exemplo do carregamento e transporte da cana colhida. Assim, diante de pressupostos limites que apontam para a permanência do trabalho manual nos canaviais, em meados dos anos de 1990, é que vão se sobressair algumas medidas de intensificação da produção agrícola.

Dentre as diversas estratégias competitivas desenvolvidas pela agroindústria alagoana, seguindo as tendências do mercado brasileiro, em especial da agroindústria paulista, destaca-se aquela na qual nos parece recaírem alguns impactos em relação à força de trabalho: "especialização na produção de açúcar e álcool e aumento da produtividade das unidades industriais e agrícolas, buscando a redução dos custos de transação e da complexidade de coordenação da cadeia produtiva" (CARVALHO, 2009, p. 74, grifos nossos).

Consoante o momento contemporâneo de reestruturação produtiva, a racionalização do trabalho nos canaviais consistiu numa estratégia "orientada para uma "redução gradativa" do contingente de trabalhadores, a partir, mas não só, da intensificação da exploração do trabalho" (PADRÃO, 1997, p. 138).

No que tange ao trabalho na parte agrícola, a busca da competitividade setorial, articulada ao novo padrão de acumulação flexível, implicou o aumento de sua produtividade por meio da constituição de novas relações entre capital e trabalho. Dentre os elementos que conjugam essas relações está a nova condição salarial, pautada pela formalização da força de trabalho (PADRÃO, 1997). A partir de então, as relações entre capital agroindustrial e trabalho canavieiro assalariado, tenderam a vincular-se diretamente através de contratos formais.

Revisitando o passado, antes dessas mudanças, a força de trabalho era empregada, majoritariamente, de maneira clandestina (informal). A emergência da formalização do trabalho canavieiro, percebida pelos trabalhadores com a disseminação das carteiras assinadas, e acesso a direitos e seguridade social inscritos no direito laboral, rompe um quadro de clandestinidade que estruturou o trabalho entre as décadas de 60 e 80, nas regiões canavieiras no Nordeste brasileiro.

É o que se pode apreender ao revisitar a literatura sobre os trabalhadores assalariados na região canavieira do Nordeste. Assim, antes da formalização, a utilização da força de trabalho se dava sem o estabelecimento de vínculo empregatício, com a presença do trabalho clandestino.

A noção de trabalho clandestino remete à maneira de assalariamento dos trabalhadores rurais que não percebem contratos de trabalho formais, e são empregados por intermediadores sem a carteira assinada, na região canavieira do Nordeste (SIGAUD, 1979).

Segundo Andrade (1994, p. 212), para o trabalhador clandestino ${ }^{17}$ :

${ }_{17}$ Cf. Andrade (1994, p. 203, adendo nosso): “[...] nas primeiras décadas do século [XX] não se usava, no Nordeste, o nome de boia-fria, clandestino ou volante, mas o de 'trabalhador de rua'". O mesmo autor salienta que o termo boia-fria permanece circunscrito aos 


\section{Formalização e precarização do trabalho canavieiro em tempos de reestruturação produtiva.}

[...] não havia garantias trabalhistas, porque, não havendo contrato entre o trabalhador e a usina, o responsável jurídico pelos direitos era o gato ou intermediário, que quase sempre não tinha idoneidade financeira. Essa política, mantida durante quase duas décadas, deu origem à figura do trabalhador volante, chamado no Nordeste, de 'clandestino', uma vez que não tinha carteira de trabalho assinada.

Assim, da forma em que as relações sociais de trabalho aparecem, o trabalho clandestino ${ }^{18}$ apresenta-se como uma relação baseada na informalidade, e se opõe, portanto, ao trabalho formal, relação estabelecida por meio de contratos e a carteira assinada, que na região é conhecido pelo termo de fichado.

Essas duas categorias, clandestinos e fichados, que aparecem na região canavieira, representam, portanto, formas diferentes de inserção laboral em relação às condições previstas em lei na maneira de vínculo com o capital agroindustrial.

A formação de um dispositivo jurídico em torno do assalariamento formal data de 1943, com a decretação da Consolidação das Leis do Trabalho (CLT), porém, só alcançou o meio rural e os trabalhadores a partir de 1963, com a criação do Estatuto do Trabalhador Rural (ETR), que concedia a estabilidade no trabalho. Todavia, o ETR surtiu o efeito contrário de ampliação da utilização de formas de trabalho temporárias e eventuais, que não estavam cobertas pela legislação, conforme analisam Silva (1999) e Stolcke (1986). Fato este que só será contornado na atualidade com a formalização dos contratos. É como se a formalização no presente reatualizasse a intermitência do trabalho no passado, dessa vez no âmbito jurídico.

Com efeito, essa transição entre os momentos de clandestinidade e formalidade nas relações de trabalho, alude a um processo mais geral de radicalização das condições de existência do trabalhador assalariado livre, quando da configuração de uma condição salarial na agricultura.

Mudanças que emergem no contexto da retomada "modernização" da agroindústria canavieira, em 1990, e têm efeitos diretos para o conjunto das relações sociais na região, quando tomamos como central para o entendimento da sociedade estudada, as relações de trabalho.

Em que pese o histórico de uma categoria social que sempre esteve à margem das proteções sociais do mercado de trabalho, nesse momento de

trabalhadores do Sudeste, e que o termo volante ou clandestino só aparece a partir dos anos de 1960, momento em que ocorre a proletarização do trabalhador rural,

${ }^{18}$ Cf. Dicionário Priberam (2010), o vocábulo “clandestino" é um adjetivo que qualifica algo:

(i) Feito sem as formalidades legais, e até evitando-as; e (ii) Feito às escondidas. 
reestruturação produtiva da agroindústria canavieira, assiste-se à produção da condição salarial formal, sintomática da ampliação dos cumprimentos da legislação trabalhista no campo.

Não trilhando a direção do binômio campo/cidade no estudo do fenômeno, compreende-se que essa nova forma de contratação guarda continuidades com os outros setores do mercado de trabalho, porquanto é nesse momento que aquelas relações de trabalho são atravessadas pelo conjunto de elementos característicos das relações de trabalho no Brasil, mormente nos contextos urbanos, a partir dos anos de 1990, a saber, a flexibilização dos direitos e instauração de formas precárias de trabalho e de empregos instáveis. Todavia, qual a marca distintiva e específica desse novo momento a se inscrever na relação laboral canavieira?

\section{Formalização e precarização do trabalho}

Ao que parece, a formalização do trabalho teve um papel central para conseguir reproduzir uma força de trabalho que no tempo da clandestinidade vivenciara uma "elevada rotatividade". Contudo, a emergência do assalariamento formal não se deu casualmente, sendo antes, possibilitada, entre outros fatores, pela introdução da racionalização e da "maximização do trabalho" nos canaviais alagoanos (PADRÃO, 1997).

Em um estudo sobre a maior usina de Alagoas, observa-se que a partir dos anos de 1990 esteve em curso um processo de redução gradativa do contingente de trabalhadores de 6.000 para 2.800 (PADRÃO, 1997, p. 138). Segundo o autor, esse "enxugamento" do número de trabalhadores canavieiros fora decorrente de uma rigorosa política de seleção e uma não menos rigorosa política educativa, "destinada à formação de um 'novo trabalhador da cana', o que efetivamente teria lugar a partir da introdução de múltiplos aparatos de controle e disciplina da mãode-obra empregada" (PADRÃO, 1997, p. 139). Essas "políticas" consistiram em formas de gestão da força de trabalho que, se por um lado impuseram uma produtividade diária elevada como resultado individual de cada trabalhador, por outro exprimem a tentativa de estimular o compromisso do conjunto dos trabalhadores agrícolas para com as metas da usina.

Com efeito, a partir de mudanças no departamento agrícola da agroindústria e nas relações sociais que este engendra, conseguiu-se naquele momento produzir um novo padrão de relações de trabalho, marcado por um maior controle do processo de trabalho, pela maximização crescente da produtividade de cada trabalhador e pelo assalariamento formal com a contratação efetivamente temporária. Ainda nas palavras do supracitado autor, "importa ressaltar que, segundo a gerência, foi somente a partir do 'enxugamento' decorrente do alcance destas políticas que a empresa 'partiu para o fichamento' do conjunto da força de trabalho empregada" (PADRÃO, 1997, p. 139). 


\section{Formalização e precarização do trabalho canavieiro em tempos de reestruturação produtiva.}

A forma de contratação é alterada, a partir dos anos de 1990, no bojo da reestruturação produtiva da agroindústria canavieira alagoana, e a formalização atinge a maioria dos contratos de trabalho na parte agrícola. Conforme afirma Albuquerque (2009, p. 92):

O que tem predominado é o trabalho temporário regido pela legislação trabalhista. Os contratos, em geral, são firmados no início de setembro, quando a safra começa, e encerrados com o fim da safra que tem um tempo médio de cinco meses, chegando, no máximo, a seis. Os contratos temporários, são nesses termos, muito mais favoráveis às usinas, que se garantem de futuras ações na justiça e não são obrigadas a pagar aviso prévio aos trabalhadores. Do lado dos trabalhadores são comuns as reclamações, especialmente porque o trabalhador dispensado não tem direito ao seguro desemprego, uma vez que o contrato safrista não o beneficia com esse direito.

Curiosamente, o setor que estudamos, dentre outros onde a formalização estava em processo, está na contramão de uma tendência em geral do mercado de trabalho brasileiro na mesma época. Segundo Noronha (2003, p. 115): “o início dos anos de 1990 representou uma ruptura no movimento crescente de formalização do trabalho. Desde então, tem crescido a 'informalidade' [...]".

Esse fato, longe de demonstrar um imediato continuum com as formas sobre as quais (re)aparecem o assalariamento em outros setores do mercado de trabalho na década de 1990, suscita a interpretação de mais elementos empíricos. Se a partir dos anos de 1990, em outros setores a terceirização e a informalidade se impõem em arranjos produtivos flexíveis e dotados de sofisticadas tecnologias que aumentam os resultados do trabalho, no nosso caso, esse aumento dos resultados do trabalho ocorreu mediante o estabelecimento da contratação formal, mas flexível, usufruindo o trabalho de maneira intermitente.

Pari passu ao maior acesso a garantias e direitos via o estabelecimento dos contratos de trabalho, novas exigências são colocadas aos trabalhadores, principalmente de um ponto de vista do processo de trabalho: mais intenso, uma jornada mais longa; um novo perfil de um trabalhador busca ser moldado: mais produtivo, mais eficiente, mais disposto a ceder às exigências feitas pelos seus "superiores", prepostos das usinas. Talvez aqui encontremos uma chave de descontinuidade em relação ao trabalhador não formalizado da história recente, sobretudo nas formas de submissão contemporâneas a uma atividade laboral que 
passou por um processo de intensificação. Pressupõe-se que a formalização parece jogar um papel fundamental para o novo conteúdo e forma de trabalho precário.

Um duplo movimento, de caráter ambivalente, fora realizado no que tange à organização do trabalho canavieiro, a partir da década de 1990: de um lado, ocorreu o recrudescimento de práticas tayloristas, ensejando um one best way nos canaviais, que prescreve exigências no processo de trabalho manual intensificandoo por meio de controles rígidos, inclusive fazendo-se uso de novas tecnologias de controle da produção individual do trabalhador; de outro, a flexibilidade se instala como norma, no estabelecimento de contratos de trabalho diretos entre usineiros e trabalhadores, sob uma temporalidade intermitente, conforme o pêndulo produtivo da lavoura canavieira, tornando social o ciclo natural safra-entressafra, a ser vivenciado nos tempos de trabalho e tempos de não trabalho dos canavieiros, entre idas e vindas dos canaviais.

A novidade é que em tempos de reestruturação produtiva, todo um antigo conjunto de práticas no universo do trabalho canavieiro é racionalizado e normatizado, e esses dois elementos, rigidez e flexibilidade, tornam-se recíproca e combinadamente interdependentes.

Compartilhando da abordagem de Linhart (2005) sobre o processo de taylorização nas relações de trabalho, a objetivação do tempo de trabalho canavieiro, inscreve-se na definição do seu tempo efetivo de trabalho, sua organização e seu controle. Na mesma tacada, esse tempo de trabalho se instaura flexivelmente, entre contratações e demissões, a partir da norma salarial estipulada em convenção coletiva, na condução da antiga flexibilidade fora da norma para a normalidade da flexibilidade, cujos contornos são mais bem visíveis, quanto maior for a abrangência dos contratos formais.

A instabilidade dos contratos formais e flexíveis repercute na fragilização do coletivo de trabalho, esta remente à individualização da relação salarial, configurando um novo momento na dominação do capital sobre o trabalho. Pari passu, a instalação da one best way nos canaviais, ao basear-se em uma organização do tempo socialmente necessário rígido e intensificado em seu processo de trabalho tornou possível agregar mais trabalho com menos trabalhadores, em menos tempo, com menos custos, favorecendo a institucionalização da instabilidade do coletivo de trabalho

$\mathrm{Na}$ aparente tensão entre rigidez e flexibilidade, repousa a formalização do trabalho canavieiro, quando da emergência do moderno assalariamento baseado em contratos de trabalho formais entre trabalho e capital que passa a regular as relações de trabalho.

A formalização dissolve a tensão entre rigidez e flexibilidade posto que ela carrega, a um só momento, um efeito de justificação para uma e para a outra. Ante um histórico de informalidade e negação dos direitos laborais e sociais, a formalização dissolve os efeitos da maneira de dispor do tempo de trabalho e da 


\section{Formalização e precarização do trabalho canavieiro em tempos de reestruturação produtiva.}

quantidade de trabalho dispendida, justificando-se pela via dos direitos concedidos, com que orquestra a legitimidade social e política onde não necessariamente repousam relações de trabalho que preservam a dignidade do trabalhador.

Destarte, a formalização do trabalho é instrumentalizada na produção canavieira: torna-se elemento de legitimação da organização do trabalho canavieiro, e ao mesmo tempo, elemento de barganha no conjunto do coletivo dos trabalhadores canavieiros. Cabe lembrar: o trabalho clandestino não fora totalmente extinguido das regiões canavieiras em Alagoas, e a qualquer vacilo, o trabalhador pode vir a cair na clandestinidade novamente.

Ao mesmo tempo, a instrumentalização dos direitos elaborada na formalização do trabalho encerra um efeito de justificação da contradição entre capital e trabalho, encobrindo a exploração e degradação das condições de trabalho, saúde e vida dos trabalhadores canavieiros de Alagoas.

\section{Considerações finais}

A formalização do trabalho rural canavieiro se aprofundou na década de 1990, coincidindo com o período em que se introduziram processos de reestruturação produtiva na agroindústria canavieira de Alagoas.

Buscou-se deslindar as determinações gerais da reestruturação produtiva através das definições do que se entende pelo fenômeno. Dentre outros aspectos, aparecendo neste texto como uma nova via de subordinação do trabalho ao capital caracterizada pelo aviltamento das condições formais e concretas - isto é, do emprego e do processo de trabalho - no usufruto da capacidade laboral dos sujeitos.

Destarte, uma nova maneira de subordinação do trabalho ao capital pode (re)aparecer inclusive em formas nada inovadoras daquela relação. Outrossim, o assalariamento formal canavieiro, exemplo aqui tomado, expressa a radicalização do moderno trabalhador assalariado em sua modalidade mais atual: essa seria, no nosso entender, uma atualização salarial da formalização já presente em contextos urbanos (e reticentemente presente em contextos rurais) há pelo menos 50 anos.

O desenvolvimento atual das relações entre capital e trabalho em um plano formal, marcado por contratos legais entre aqueles sujeitos indica, sobretudo, uma mudança na cultura organizativa da produção canavieira, seja simbólica, seja objetiva, que se opera no coração do operariado agrícola de Alagoas. Dessa maneira, os significados particulares da reestruturação produtiva, na base territorial daquele estado, são incorporados na análise.

Esta tentou asseverar uma espécie de hipótese de trabalho, ainda em curso de sua aplicação - a ser examinada com referencia na realidade empírica -, da 
pertinência do modelo taylorista de conceber o esforço do trabalho vis-à-vis o modelo flexível de manipular a intermitência da inserção laboral, ambos os aspectos constituindo-se como vetores da formalização do trabalho naquela atividade.

\section{Referências}

ALBUQUERQUE, Cícero Ferreira de. Cana, casa e poder. Maceió: EDUFAL, 2009. ALVES, Giovanni. O novo (e precário) mundo do trabalho: Reestruturação produtiva e crise do sindicalismo. São Paulo: Boitempo, 2000.

ANDRADE, Manuel Correia de. Modernização e Pobreza: a expansão da agroindústria canavieira e seu impacto ecológico e social. São Paulo: Editora da Universidade Estadual Paulista, 1994.

ANTUNES, Ricardo. Adeus ao trabalho? 5. ed. São Paulo: Cortez; Campinas: Editora da Universidade Estadual de Campinas, 1998.

APPAY, Béatrice. Précarisation sociale et restructurations productives. In: APPAY, B.; THÉBAUD-MONY A. (Orgs.) Précarisation sociale, travail et santé. Paris: CNRS, IRESCO/Inserm, 1997, p. 509-558.

BIHR, Alain. Du "Grand Soir" a "L'Alternative" : le mouvement ouvrier europeén en crise. Pairs : Les Editions Ouvrières, 1991.

La précarité gît au coeur du rapport salarial - Une perspective marxiste. In

?Interrogations? - Revue pluridisciplinaire en sciences de l'homme et de la sociéte. Numéro 4. Formes et figures de la précarité. Juin 2007. Disponível em: http://www.revue-interrogations.org. Acesso em: 20 jun. 2011.

CARDOSO Jr., José Celso. Crise e desregulação do trabalho no Brasil. In: Tempo Social; Revista de Sociologia da USP, São Paulo, v. 13, n. 2, p. 31-59, novembro de 2001.

CARVALHO, Cícero Péricles de. Análise da reestruturação produtiva da agroindústria sucroalcooleira alagoana. 3. ed. Maceió: EDUFAL, 2009.

COMPANHIA NACIONAL DE ABASTECIMENTO (CONAB). Acompanhamento de safra brasileira: cana-de-açúcar, terceiro levantamento, janeiro/2011. Brasília: Conab, 2011. Disponível em: http://www.conab.gov.br/OlalaCMS/uploads/arquivos/11 $010609 \quad 14$

50 boletim cana 3o lev safra 2010 2011..pdf. Acesso em: 10 jan. 2011.

DEMAZIÈRE, Didier. Précarités d'emploi, précarités de condition: entre formes et normes. In: Anais do Colóquio Internacional "Novas formas do trabalho e do desemprego: Brasil, Japão e França numa perspectiva comparada". São Paulo: $2006 . \quad$ Disponível em: http://www.centrodametropole.org.br/v1/textos nadya/Demazi re.pdf. Acesso em: 15 jan. 2012. 


\section{Formalização e precarização do trabalho canavieiro em tempos de reestruturação produtiva.}

DRUCK, Graça; FRANCO, Tânia. Terceirização: a chave da precarização do trabalho no Brasil. In: NAVARRO, Vera Lucia e PADILHA, Valquíria. Retratos do trabalho no Brasil. Uberlândia: Edufu, 2009, p.225-254.

GORZ, André. Adeus ao proletariado: para além do socialismo. Rio de Janeiro: Forense Universitária, 1987.

HARVEY, David. Condição pós-moderna. Uma pesquisa sobre as origens da mudança cultural. 18. ed. São Paulo: Edições Loyola, 2009.

HEREDIA, Beatriz Maria Alasia. Formas de dominação e espaço social: a modernização da agroindústria canavieira em Alagoas. São Paulo: Marco Zero; Brasília: MTC/CNPq, 1988.

HUMBLET, Patrick; DORSSEMONT, Filip. Travail précaire et droit au travail ou comment l'Etat régule-t-il la flexploitation. In: VRANKEN J.; LAHAYE W.; GEERTS A.; COPPEE C. (Orgs.). Pauvreté en Belgique. Annuaire 2012, Leuven, Acco, 2012, p. 245-260.

KREIN, José Dari. As formas de contratação flexível no Brasil. In:

Tendências recentes nas relações de emprego no Brasil: 1990-2005. 2007. Tese de Doutorado. Universidade Estadual de Campinas, Campinas.

LINHART, Danièle. Le contrat de travail salarié: um quiproquo fondamental. In: LINHART, Danièle; MOUTET, Aimée. Le travail nous est compté: La construction des normes temporelles du travail. Paris: La Découverte, 2005.

MARCELINO, Paula. "As palavras e as coisas": Uma nota sobre a terminologia dos estudos contemporâneos de trabalho. In: Mediações: Revista de Ciências Sociais, Londrina, v. 16, n. 1, p. 55-70, jan./jun. 2011. Disponível em: http://www.uel.br/revistas/uel/index.php/mediaco es/article/view/7914/8487. Acesso em: 15 nov. 2011.

PADRÃO, Luciano Nunes. O trabalho na cana-de-açúcar. Reestruturação produtiva e novas práticas gerenciais. 1997. Disponível em: http://www.seade.gov.br/produtos/spp/ v11n01/v11n01 14.pdf. Acesso em: 15 out. 2008.

QUEIROZ, Allan Souza. Modernização, reestruturação produtiva e precarização do trabalho nos canaviais alagoanos. Trabalho de Conclusão de Curso. Maceió: Universidade Federal de Alagoas, 2011.

SÁNCHEZ, Arturo Lahera. "Conquistando los corazones y las almas de los trabajadores": la participación de los trabajadores en la calidad total como nuevo dispositivo disciplinario. In: CASTILLO, Juan José. El trabajo recobrado. Una evaluación del trabajo realmente existente en España. Buenos Aires: Miño y Dávila, 2005.

SIGAUD, Lygia. Os clandestinos e o direito: estudo sobre trabalhadores da cana-deaçúcar de Pernambuco. São Paulo: Duas Cidades, 1979. 
SILVA, Maria Aparecida de Moraes. Errantes do fim do século. São Paulo: Fundação Editora da UNESP, 1999.

STOLCKE, Verena. Cafeicultura. Homens, mulheres e capital (1850-1980). São Paulo: Brasiliense, 1986.

THEBAUD-MONY, Annie. Precarização social do trabalho e resistências para a (re)conquista dos direitos dos trabalhadores na França. In: Caderno CRH, Salvador,

v. 24, n. esp. 01, p.23-35, 2011. Disponível em:

http://www.scielo.br/scielo.php?script=sci arttext \&pid=S010349792011000400003\&lng=pt\&nrm=iso\&tlng=pt. Acesso em: 15 dez. 2011.

VASAPOLLO, Luciano. O trabalho atípico e a precariedade. São Paulo: Expressão Popular, 2005. 